\author{
Journal of Social Economics Research \\ 2021 Vol. 8, No. 2 pp. 96-107. \\ $\operatorname{ISSN}(e): 2312-6264$ \\ $\operatorname{ISSN}(p):$ 2312-6329 \\ DOI: 10.18488/journal.35.2021.82.96.107 \\ (C) 2021 Conscientia Beam. All Rights Reserved. \\ check for
updates
}

\title{
HUMAN RESEARCH MANAGEMENT: EFFECT OF COVID-19 ON WORKERS IN THE UK WHO HAVE PREVIOUSLY LOST ONE OR BOTH ARMS
}

iD Stavros
Kalogiannidis $^{1+}$
iD Olympia
Papaevangelou

\section{Article History}

Received: 14 July 2021

Revised: 12 August 2021

Accepted: 3 September 2021

Published: 22 September 2021

\section{Keywords}

Disability

COVID-19 pandemic

Working from home

Stigma

Discrimination

Change in wages

Human resource management.

\author{
'Department of Regional and Cross Border Development, University of \\ Western Macedonia, Greece. \\ Email: stavroskalogiannidis@gmail.com Tel:00306947447761 \\ ${ }^{2}$ Secondary \& Postsecondary Educator, Ministry of Education, Kozani, \\ Greece. \\ Email:olympia.papaevangelou@gmail.com Tel:00306976175035
}

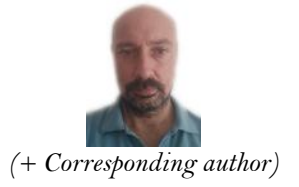

ABSTRACT

\section{JEL Classification:}

\begin{abstract}
The study aims to establish the impact of COVID-19 on the workers who have previously lost one or both arms. The study was motivated by the increased need to establish the current status of disabled workers during the coronavirus pandemic. The study also seeks to establish the effect of change in wages and working from home during the pandemic on the productivity of workers who have lost one or both arms. The pandemic has impacted several sectors across the world, both socially and economically. However, there is limited research targeting workers with disabilities. The study adopted a cross-sectional survey design where data was collected from 100 workers from the UK using an online questionnaire. The findings indicated that working from home and changing wages reduced the productivity of these employees. Workers who remained at their workplaces reported incidences of stigma and discrimination from stressed fellow employees.
\end{abstract}

A10.

Contribution/Originality: This study is one of the few studies investigating the impact of COVID-19 on human resource management, especially concerning workers who have previously lost one or both of their arms.

\section{INTRODUCTION}

\subsection{Background of the Study}

The COVID-19 pandemic has disproportionately affected those who have encountered substantial hurdles to working in the past, particularly individuals with disabilities, exacerbating the economic problems many people with disabilities endured before the outbreak. People with disabilities have historically had lower employment rates and receive considerably lower salaries than their peers without impairments (ILO, 2020). According to UNHCR (2021), just $36 \%$ of individuals with disabilities are working compared to $77 \%$ of the general population. Workers with disabilities make up just two-thirds as much as the typical worker without a handicap, according to a 2019 Census Bureau study. People with disabilities have faced lost earnings, job loss, and long-term unemployment due to the pandemic's heightened health risks and the higher risk of exposure in many industries where face-to-face contact is unavoidable. Governors and state officials must be aware of these implications for individuals with disabilities to guarantee that all Americans benefit from the economic recovery (Belzunegui-Eraso \& Erro-Garcés, 2020).

Disabled people are more likely to have lost their jobs as a result of the pandemic. People with disabilities have historically had a greater rate of unemployment. Before the pandemic, however, the percentage of disabled 
individuals working increased faster than that of able-bodied people, showing that the disability unemployment gap was decreasing. People with impairments, on the other hand, have been disproportionately affected by pandemicrelated layoffs. The number of employed working-age individuals with disabilities in the UK declined by $20 \%$ (950,000 people) from March to April 2020, while the number of employed working-age people without disabilities fell by $14 \%$ (ILO-OECD, 2020).

Leonard (2020) indicates that the pandemic's impact is observed across all industries in the UK. However, disabled people have been particularly hard hit, because those with underlying health conditions were classified as clinically vulnerable and instructed to shield for most of the previous year. Many people have felt uncomfortable when away from work and distanced from their coworkers (ILO, 2020).

UKaid (2020) indicates that due to the government's attempts to limit people travelling to prevent the spread of the disease, the Coronavirus crisis has resulted in an unprecedented shift toward working flexibly, including working from home. Access to flexible working arrangements, such as home-working and staggered or compressed working hours, often determines a disabled person's ability to continue working. This is an excellent chance to evaluate the long-term availability of flexible working options across the labor market. In reaction to the Coronavirus outbreak, employers are moving quickly to accommodate flexible working arrangements.

As a result of the pandemic, many businesses have had to rethink their operations and take cost-cutting measures. According to United Nations (2020), a more significant proportion of disabled employees was laid off during this pandemic than non-disabled employees. Between July and November 2020, 21,100 disabled employees were laid off compared to 13,000 non-disabled employees (Blanck, Hyseni, \& Altunkol Wise, 2020). Given that many businesses are struggling to stay afloat, figures like these imply that companies are looking for individuals who can fill various jobs.

\subsection{Problem Statement}

Disabled workers have been hit particularly hard by the pandemic. COVID-19 infections had reached 7.3 million cases globally by the beginning of June 2020, impacting almost all nations and territories (UKaid, 2020). As the number of cases and the fear of spreading the disease have grown, so have containment measures. Most nations used complete or partial lockdown procedures to reduce transmission of the virus and prohibited physical contact (Schur, Ameri, \& Kruse, 2020). While disabled employees have experienced various effects due to the pandemic, one of the most significant effects has been a reduction in working hours and, in some cases, job loss as a result of anxiety and limited mobility connected to confinement measures. Disabled workers have had a more challenging time dealing with the pandemic. However, research on the exact impacts rendered on disabled workers by COVID19 is not available. This justifies the relevance of this study in exploring the effects of COVID-19 on workers who have previously lost one or both arms, particularly in the UK.

\subsection{Objective of the Study}

The major objective of this study is to assess the effects of COVID-19 on workers who have previously lost one or both of their arms with a focus on workers from the UK. The study was also based on different specific objectives that include:

- Establishing the effect of wage changes during the COVID-19 pandemic on the productivity of workers who have lost one or both arms.

- Exploring the effect of working from home on the productivity of workers who have lost one or both arms.

\subsection{Research Question}

Adverse effects of losing an arm in the labor market - is it just stigma, or can it be explained by productivity loss? 


\subsection{Research Hypothesis}

H1: A change in wages affects the productivity of workers who have lost one or both arms.

H2: Working from home affects the productivity of workers who have lost one or both arms.

\subsection{Significance of the Study}

The study will contribute to the existing knowledge concerning the impact of COVID-19 on workers, especially those with disabilities. Furthermore, the study findings will be a reference point for future research in the same or related study areas. In this case, future researchers can use this study's findings to make necessary reviews and conclusions about COVID-19 and its impact on workers who have previously lost one or both arms.

\section{LITERATURE REVIEW}

\subsection{Introduction}

This chapter covers the review of literature related to COVID-19 and its impact on people with disabilities. This part of the study is concentrated on a review of the related books.

\subsubsection{Change in Wages and Income}

Millions of workers lost part or all of their income as the coronavirus swept throughout the world and companies shuttered (ILO-OECD, 2020). Many employees in aviation, retail and lodging, food services, and the textile and fabric sectors, mainly gendered, had to accept shorter hours and salary cuts while still working. Wage cuts were agreed upon in some instances as part of collective bargaining agreements between employees and employers. In Argentina, for example, a cooperative agreement contained a $25 \%$ salary decrease for workers in shut down industries for 60 days from April 1, 2020, to save employment. In March, 35\% of employees in the United States, $30 \%$ in the United Kingdom, and 20\% in Germany who were still in paid employment reported lower wages than in previous months (UKaid, 2020).

Various nations have also enacted pay cuts in the public sector, and labor data in certain countries show that salaries dropped. Between the week ending March 14, 2020, and the week ending June 13, 2020, the nominal average earnings for employees aged 50 to 59 years fell by $3.2 \%$ in Australia. In April, real average wages in the United Kingdom fell by $1.2 \%$ following a drop in March 2020. On the other hand, in the United States, a historic $5.8 \%$ increase in real wages occurred in April 2020, followed by a lower increase of 0.5\% in May 2020. However, this represents a compositional impact in which a larger number of low-paid employees lost their jobs than highpaid workers, raising the average wages of those who remained working. When comparing salary freezes and cuts in March, April, and May 2020 to the same months in 2019, one study indicates that wage freezes and cuts were significantly more prevalent in 2020 than in 2019. In Canada, real pay growth accelerated to 6.8\% in April 2020, reflecting more job losses for low-wage employees after a significant increase in unemployment from $8 \%$ in March to $13.4 \%$ in April (Blanck et al., 2020).

The economic costs of the COVID-19 pandemic have not been evenly distributed. Existing flaws have been highlighted and inequities have been entrenched. Those with the fewest resources have been the least equipped to defend themselves. During the early stages of the crisis, low-paid, and frequently low-skilled, workers were disproportionately affected. Many so-called "frontline employees", who put their health in danger by exposing themselves to the virus to keep vital services running during lockdowns, work in low-wage industries. Aside from doctors, this category includes cashiers, factory and food processing employees, janitors and maintenance workers, agricultural workers, delivery workers, and truck drivers (Schur et al., 2020).

Leonard (2020) indicates that the COVID-19 pandemic has had an especially devastating impact on employees in the informal economy, for whom staying at home means losing their employment and livelihoods. According to ILO projections, 1.2 billion employees in G20 nations would be employed informally in 2020, accounting for $55 \%$ of 
overall employment (ILO, 2020). The COVID-19 issue is expected to have had a significant impact on 850 million $(70 \%)$ of these workers, resulting in a $61 \%$ drop in their pay. Furthermore, relative poverty is expected to rise by about 36 percentage points for informal workers and their families in G20 nations (ILO-OECD, 2020).

\subsection{Changes in Productivity}

According to UNHCR (2021), several working from home and disability surveys were published between 2000 and 2020. They were divided into studies on available employment opportunities, work patterns and accommodations, performance, policy, and work-life balance. Most of the research looked at the possible benefits and problems of teleworking and disability without relying on or creating new empirical data.

Employers are concerned about whether productivity diminishes when their employees work from home. This was addressed in a large-scale randomized field experiment at a Chinese firm. Half of the workforce was randomly allocated to telecommuting, while the other half reported to the office (ILO, 2020). The results showed that the telecommuters had a $13 \%$ greater production rate. Furthermore, their satisfaction was found to be higher, and the staff turnover was lower. The findings appear to be supported by research that found that production did not suffer due to the move to remote work during the pandemic and previous pre-pandemic studies on remote working that found an improvement in job performance. Many firms have decided to permanently expand remote work opportunities in the wake of COVID-19 and shut down workplaces, recognizing that the remote working arrangements brought about by the pandemic enhanced employee creativity and innovation (United Nations, 2020).

Raišiene, Rapuano, Varkulevičiute, and Stachová (2020) looked at the benefits and drawbacks of teleworking for people with disabilities, finding that while it can increase opportunities for hiring people with disabilities, teleworking can also "place severe constraints on the type of work, workplace environment, and interactions, as well as the accumulation of social capital for people with disabilities". Raišiene et al. (2020) were interested in finding strategies to decrease the social isolation that many teleworkers feel and improve their engagement in the working environment, mainly because people with disabilities are more likely to be socially isolated.

McNaughton, Light, and Gulla (2003) examined the benefits and drawbacks of teleworking, emphasizing people who utilize augmentative or alternative communication methods. They discovered that a significant benefit of teleworking is the removal of travel time and the flexibility of working hours. Participants in their survey also expressed worries about feeling isolated and the difficulties of separating their personal and work lives.

\subsection{Employment of People with Disabilities}

In 2019, fewer than a third of working-age people with disabilities (30.9\%) were employed, compared to threequarters $(74.6 \%)$ of non-disabled people. Workers with and without impairments have both grown in number since the conclusion of the previous recession in 2010. Still, the disability employment rate expanded notably fast in the increasingly tight labor markets of 2015-2019 (Easterseals, 2021). From 2015 to 2019, the disability employment rate increased by 4.0 percentage points, compared to a 2.4 percentage point growth for non-disabled employees. However, the higher employment losses of workers with disabilities in the 2020 COVID recession essentially undid this relative gain. From February to July 2020, overall employment for individuals with impairments fell by $11.2 \%$, compared to $6.7 \%$ for people without disabilities (Blanck et al., 2020).

While some people with impairments face restrictions that make finding a job difficult, many others encounter other obstacles. Employers are less likely to exhibit interest in job applications from people with disabilities, even when their resumes are identical to candidates without disabilities and the disabilities are unrelated to work performance, according to employer audit studies carried out by us and others (Blanck et al., 2020).

Other studies demonstrate that once employed, many individuals with disabilities encounter unfavorable stereotypes and expectations from managers, supervisors, and coworkers, which restrict their career advancement and work-life quality, including more negative treatment from management (Schur et al., 2020; United Nations, 
2020). While the majority of coworkers accept disability-related modifications, they can occasionally cause envy and resentment. Employees with impairments suffer a wage disadvantage after accounting for productive traits such as education and job experience. They also express a lack of work security and are more likely to be laid off by their employers during difficult times. Like other members of marginalized groups, workers with impairments seem to be "last employed, first dismissed" (Leonard, 2020). These inequalities are associated with decreased job satisfaction among disabled workers while having similar organizational commitment and turnover intention as non-disabled individuals.

\subsection{Research Gap}

Several studies have previously been conducted to assess the impact of COVID-19 on workers. Most scholars have generalized workers without particularity differentiating between skilled and unskilled or disabled and nondisabled workers. Research on COVID-19 and its effect on workers with disabilities, particularly in the UK, is limited. More so, there is no study focusing on workers that have previously lost one or both arms.

\section{METHODOLOGY}

\subsection{Research Design}

Eyisi (2016) defines research design as a conceptual structure where research is conducted and establishes a basis for collecting, measuring, and analyzing data. The study used a quantitative research methodology based on a cross-sectional survey design that enabled observation of several variables and offered a deep understanding of the research subject. A cross-sectional survey research design is used because it allows the researcher to generalize the findings to a larger population of workers affected by COVID-19, particularly those with disabilities, in the UK.

\subsection{Target Population}

The current study targeted workers that have previously lost one or both arms and are working in the UK.

\subsection{Sample Size}

The sample size for this study was established using the sampling techniques of Krejcie and Morgan (1970), which resulted in a sample size of 150 workers who have previously lost one or both of their arms and are working in the UK.

\subsection{Sampling Technique}

The study utilized probability sampling techniques, particularly simple random sampling. Simple random sampling techniques helped to achieve a representative sample of workers in the UK who have previously lost one or both arms. The advantage of simple random sampling is that it creates samples that are highly representative of the population, eradicating the possibility of biased responses. However, it can be quite tedious and time-consuming, especially when creating larger samples.

\subsection{Data Collection}

Eyisi (2016) describes a questionnaire as a series of questions asked to obtain respondents' study objectives. An online questionnaire (see Appendix 1) was used to collect data from disabled workers who have previously lost one or both arms and are working in the UK.

\subsection{Measurement}

The variables were measured by defining concepts operationally. For example, the questions in the survey were designed to gather responses about the impact of COVID-19 on workers who have previously lost one or both arms 
representing the larger population of the UK. The questions were converted into measurable and observable elements to allow the development of an index concept. Categorical demographic information, experience working from home, wages, and productivity were utilized, which helped collect reliable and accurate data.

\subsection{Data Analysis}

Data collected from study participants using a questionnaire was well sorted and imported into Stata for analysis. Data were analyzed at two different levels—univariate and bivariate. The univariate analysis involved analyzing single variables and interpretation was made based on the obtained frequencies and percentages. The bivariate analysis involved using the chi-square test, which helped to establish the relationship between different study variables. Chi-square was used to test hypotheses using the formula presented in Equation 3.1 below:

$$
X^{2}=\frac{\Sigma(\text { Sum of (Observed -Expected })^{2}}{\text { Expected }}
$$

The chi-square analysis results were interpreted based on the obtained chi-square values and P-values, which formed the basis for rejecting or accepting the null hypothesis at the 0.05 critical value.

\subsection{Logistic Regression}

Logistic regression is the appropriate analysis when the dependent variable is dichotomous (binary) or categorical. It was used to determine how independent variables predict the dependent variable and the relationship between the variables.

The assumptions for using logistic regression are as follows:

a) The dependent variables should be dichotomous.

b) There should be no outliers in the data.

c) There should be no high correlation (multicollinearity).

The logit model was stated, as presented in Equation 3.2 below:

$$
\text { logit } \epsilon(Y)=\beta+\beta_{1} x_{1}+\beta_{2} x_{2}
$$

Where $Y$ is the Bernoulli-distributed response variable, $x$ is the predictor variable, and the $\beta$ values are the linear parameters.

\subsection{Ethical Considerations}

Different ethical requirements must be put into consideration if any research study is to be successful. The researcher ensured that the respondents were informed about the details of the study and had willingly consented to participate. The researcher also observed a high level of confidentiality and privacy when handling the data collected from respondents.

\section{RESULTS}

\subsection{Introduction}

This chapter covers the presentation and interpretation of the results obtained after analysis using Stata.

Table 1 presents results regarding the demographic characteristics of the study participants.

\subsection{Univariate Analysis}

Results in Table 1 show that more than half of the participants (59.3\%) were male, and only $37.3 \%$ were female. The majority of the disabled workers (35.3\%) were aged 26-35 years, and the 18-25 age group contained the fewest participants $(8 \%)$. The majority of the workers $(45.3 \%)$ had spent $6-11$ years with the disability, and the fewest 
number of participants had spent between 0 and 5 years with the disability. The average monthly wages before the pandemic for most of the participants $(44.7 \%)$ was above $£ 4,000$, and only $9.3 \%$ were earning less than $£ 1$, O00. However, the average monthly wages after the pandemic for the majority of the workers $(35.3 \%)$ was $£ 1001-$ $£ 2,000$, and only $13.3 \%$ were earning above $£ 4,000$.

Table 1. Demographic data of participants.

\begin{tabular}{|c|c|c|}
\hline Characteristic & Frequency & Percentage (\%) \\
\hline \multicolumn{3}{|l|}{ Gender } \\
\hline Male & 94 & 62.7 \\
\hline Female & 56 & 37.3 \\
\hline \multicolumn{3}{|l|}{ Age bracket } \\
\hline $18-25$ & 12 & 8.0 \\
\hline $26-35$ & 39 & 26.0 \\
\hline $36-45$ & 53 & 35.3 \\
\hline $46-55$ & 19 & 12.7 \\
\hline Above 55 years & 27 & 18.0 \\
\hline \multicolumn{3}{|l|}{ Education level } \\
\hline Certificate & 12 & 8.0 \\
\hline Diploma & 32 & 21.3 \\
\hline Bachelors & 86 & 57.3 \\
\hline Masters & 11 & 7.4 \\
\hline PhD & 9 & 6.0 \\
\hline \multicolumn{3}{|l|}{ Years of disability } \\
\hline $0-5$ & 9 & 6.0 \\
\hline $6-11$ & 68 & 45.3 \\
\hline $12-17$ & 21 & 14.0 \\
\hline More than 17 & 52 & 34.7 \\
\hline \multicolumn{3}{|c|}{ Average monthly wages before the pandemic } \\
\hline Less than $£ 1000$ & 14 & 9.3 \\
\hline$£ 1001-£ 2,000$ & 39 & 26.0 \\
\hline$£ 2001-£ 4,000$ & 30 & 20.0 \\
\hline Above $£ 4,000$ & 67 & 44.7 \\
\hline \multicolumn{3}{|c|}{ Average monthly wages after the pandemic } \\
\hline Less than $£ 1000$ & 43 & 28.7 \\
\hline$£ 1001-£ 2,000$ & 53 & 35.3 \\
\hline$£ 2001-£ 4,000$ & 34 & 22.7 \\
\hline Above $£ 4,000$ & 20 & 13.3 \\
\hline Total & 150 & 100 \\
\hline
\end{tabular}

\subsection{Descriptive Statistics}

The study sought to establish whether the workers were forced to work from home following the pandemic, and the results are presented in Figure 1.

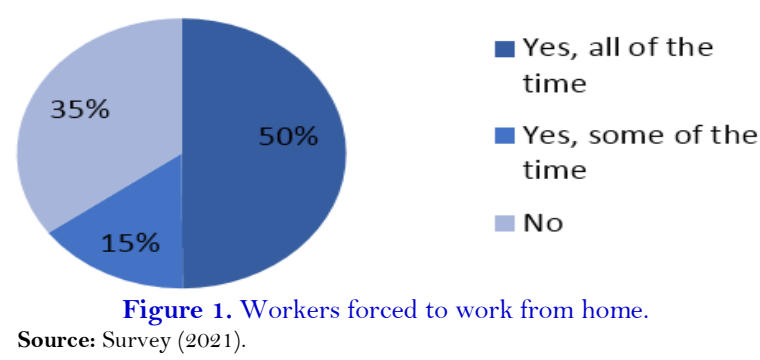

Half of the study participants (50\%) revealed that they worked from home, 35\% some of the time worked from home and only $15 \%$ did not work from home. These results meant that most workers who had previously lost one or both arms had been forced to work from home due to the difficulties of travelling to the workplace during the 
COVID-19 pandemic. The study further focused on establishing whether employers offered help concerning new work adjustments in the pandemic, and the results are presented in Figure 2.

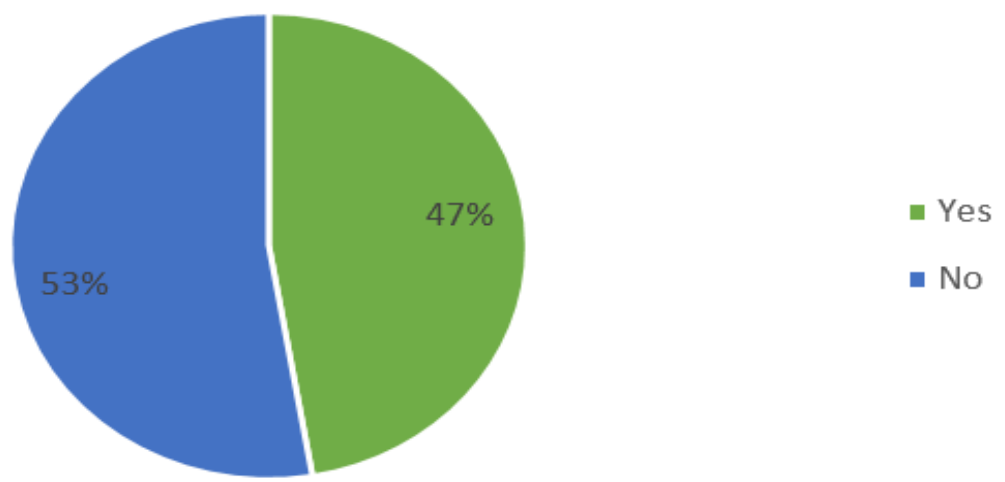

Figure 2. Employers offered help following new work adjustments. Source: Survey (2021).

The majority of the workers (53\%) indicated that they did not receive any special provisions from their employers following the work adjustments during the pandemic.

Respondents were also asked to indicate their productivity levels following work adjustments during the pandemic, and the results are presented in Figure 3.

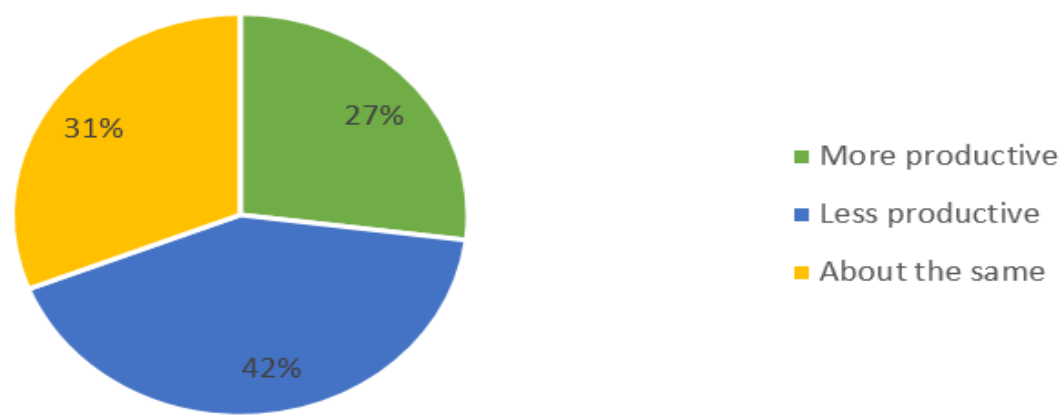

Source: Survey (2021).

Figure 3. Level of productivity.

The majority of the participants $(42 \%)$ indicated that they were less productive following the work adjustments during the pandemic, $31 \%$ felt that their level of productivity had not changed, and $27 \%$ indicated that they were more productive.

\subsection{Chi-square Analysis}

A chi-square analysis was used to establish the relationship between the different study variables, and the results are presented in the tables below:

Table 2. Cross-tabulation between working from home and productivity.

\begin{tabular}{l|c|c|c|c}
\hline & \multicolumn{3}{|c|}{ Working from home } & \\
\hline Productivity & Yes, all of the time & Yes, some of the time & No. & Total \\
\hline More productive & 11 & 7 & 2 & 20 \\
\hline Less productive & 63 & 27 & 7 & 97 \\
\hline About the same & 15 & 13 & 5 & 33 \\
\hline Total & 89 & 47 & 14 & 150 \\
\hline$\chi^{2}=6.2534$ & $\mathrm{df}=3 \quad \mathrm{p}=0.036$ & $\alpha=0.05$ \\
\hline
\end{tabular}


The results in Table 2 show that the computed $\chi_{\mathrm{c}}^{2}=6.2534$ is greater than the tabulated $x^{2}=3.841$ and $\mathrm{p}=$ $0.036<0.05$; thus, we reject the null hypothesis and conclude that working from home has a significant effect on the productivity of the study participants.

Table 3. Cross-tabulation of average monthly wages after the pandemic and productivity.

\begin{tabular}{|c|c|c|c|c|c|}
\hline \multirow[t]{2}{*}{ Productivity } & \multicolumn{4}{|c|}{ Average monthly wages after the pandemic } & \multirow[t]{2}{*}{ Total } \\
\hline & Less than $£ 1000$ & $\mathscr{L} 1001-\mathscr{L 2 , 0 0 0}$ & 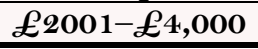 & Above $\mathscr{E 4 , 0 0 0}$ & \\
\hline More productive & 4 & 6 & 9 & 1 & 20 \\
\hline Less productive & 11 & 27 & 56 & 3 & 97 \\
\hline About the same & 9 & 6 & 14 & 4 & 33 \\
\hline Total & 98 & 32 & 9 & 11 & 150 \\
\hline$\chi^{2}=5.578$ & $\mathrm{df}=3$ & $\mathrm{p}=0.022$ & & $=0.05$ & \\
\hline
\end{tabular}

The results in Table 3 show that the computed $\chi_{\mathrm{c}}^{2}=5.578$ is greater than the tabulated $x^{2}=3.841$ and $\mathrm{p}=$ $0.022<0.05 ;$ we therefore reject the null hypothesis and conclude that a change in wages affects workers' productivity.

\subsection{Logistic Regression}

This was used to establish how the categorical independent variables influence employee membership in labor unions. The results are presented in Table 4.

Table 4. Logit regression analysis.

\begin{tabular}{|c|c|c|c|c|}
\hline Model & Coef. & Std. Error & $\mathbf{P}>|\mathbf{z}|$ & [95\% conf. interval] \\
\hline (Constant) & -2.864598 & 0.385381 & 0.000 & $-3.619931-2.109265$ \\
\hline Average monthly wages after the pandemic & -0.1638384 & 0.1354333 & 0.026 & $-0.4292828 \quad 0.101606$ \\
\hline Working from home & 0.0781313 & 0.0755177 & 0.041 & $-0.0698808 \quad 0.2261434$ \\
\hline \multicolumn{5}{|l|}{ Dependent variable: Productivity of workers } \\
\hline \multicolumn{5}{|l|}{ Number of obs.: 50} \\
\hline \multicolumn{5}{|l|}{ Log likelihood: -113.0459} \\
\hline \multicolumn{5}{|l|}{ LR chi-squared(2): 2.62} \\
\hline \multicolumn{5}{|l|}{ Prob > chi-squared: 0.2697} \\
\hline Pseudo R $\mathrm{R}^{2}$ : 0.0012 & & & & \\
\hline
\end{tabular}

The results in Table 4 confirm that the two categorical variables (wages after the pandemic and working from home) have a significant influence on productivity (Prob $>$ chi2 $=0.2697<0.05$ ). In this case, the model is statistically significant because the p-value is less than 0.05. The results also show that average monthly wages after a pandemic are a significant predictor of productivity of workers who have previously lost one or both arms (P $>|z|=0.026>0.05)$ and working from home is also a significant predictor of productivity of workers who have previously lost one or both arms $(\mathrm{P}>|\mathrm{z}|=0.041>0.05)$. However, average monthly wages showed more significance compared to working from home. This indicates that the productivity of workers was greatly influenced by the wages earned during the pandemic.

\section{DISCUSSION AND CONCLUSION}

This study sought to assess the impact of the COVID-19 pandemic on workers in the UK who had previously lost one or both arms. The findings confirm a severe impact of the pandemic on the reduction of wages, reduced productivity, an increase in the number of people working from home, and discrimination against workers who remained in their workplaces. 
During COVID-19, disabled employees experienced a variety of experiences associated with work. The findings revealed that a significant number of workers were forced to work from home by their employers. However, some workers continued to work at their companies' premises and balanced both home and the workplace. Most of the workers who had previously lost one or both arms confirmed that working from home during the pandemic greatly affected their productivity. More so, the average monthly wages were much lower than before the pandemic, and this could have been the primary cause of reduced productivity among these workers. The literature established that many disabled people would benefit from working from home, and the UK has a once-in-a-lifetime opportunity to improve their working lives (Blanck et al., 2020; UKaid, 2020). Employers and the economy would gain from greater productivity and lower illness rates as a result of this. It will certainly increase the number of economically active disabled individuals. However, it is essential to ensure that home working does not result in employers failing to provide reasonable adjustments in the workplace or reducing disabled people's visibility at work.

Furthermore, homeworkers face mental health issues, isolation, and loneliness, necessitating extra investment to support them. Because only a small percentage of disabled individuals are aware of Access to Work, it remains the government's "best-kept secret". COVID-19 revealed a lack of investment and capacity, forcing it to turn down many disabled workers who needed assistance right away. It was also unclear if home working assistance was provided. Furthermore, Access to Work uses an antiquated paper-based system that is unfit for the twenty-first century.

\section{RECOMMENDATIONS}

Disabled employees should be granted a new right to work from home if they so choose, with strict enforcement and with a specified timeframe for employers to respond to requests and implement changes. This should be a choice, with individuals who wish to stay at work having the right to reasonable accommodations to make their job accessible.

The right to reasonable accommodations, both for employees with disabilities and for non-disabled workers, should be better enforced in law.

To allow a dramatic roll-out of homeworking, the government should establish a new budget specifically for equipment, which would pay for goods such as computer equipment, desks, and seats, among other things.

The government should invest in Access to Work so that disabled people who might benefit from it have better choices when working from home.

The government should also enact strict laws to ensure that workers with disabilities are not paid below their input. In this case, the wages rendered should be in line with their level of input at work.

Funding: This study received no specific financial support.

Competing Interests: The authors declare that they have no competing interests.

Acknowledgement: Both authors contributed equally to the conception and design of the study.

\section{REFERENCES}

Belzunegui-Eraso, A., \& Erro-Garcés, A. (2020). Teleworking in the context of the Covid-19 crisis. Sustainability, 12(9), 3662. Available at: https://doi.org/10.3390/su12093662.

Blanck, P., Hyseni, F., \& Altunkol Wise, F. (2020). Diversity and Inclusion in the American legal profession: Workplace accommodations for lawyers with disabilities and lawyers Who identify as LGBTQ. Journal of Occupational Rehabilitation, 30(4), 537-564. Available at: https://doi.org/10.1007/s10926-020-09938-3.

Easterseals. (2021). Easterseals study on the impact of COVID-19 on people with disabilities, may, 2-7. Retrieved from: https://www.easterseals.com/shared-components/document-library/media-room/easterseals-study-on-the-impact-ofcovid-summary.pdf. 
Eyisi, D. (2016). The usefulness of qualitative and quantitative approaches and methods in researching problem-solving ability in science education curriculum. Journal of Education and Practice, 7(15), 91-100.

ILO-OECD. (2020). The impact of the COVID-19 pandemic on jobs and incomes in G20 economies, 46. Retrieved from: https://www.ilo.org/wcmsp5/groups/public/---dgreports/---cabinet/documents/publication/wcms_756331.pdf.

ILO. (2020). Current situation: Why are labour markets important? 1-5. Retrieved from: https://www.ilo.org/wcmsp5/groups/public/---dgreports/---dcomm/documents/briefingnote/wcms 738753.pdf.

Krejcie, R. V., \& Morgan, D. W. (1970). Determining sample size for research activities. Educational and Psychological Measurement, 30(3), 607-610. Available at: https://doi.org/10.1177/001316447003000308.

Leonard, C. (2020). Policy briefing: Employment and Covid-19 overview. Retrieved from: https://www.leonardcheshire.org/sites/default/files/2020-04/Employment-Coronavirus-policy-briefing.pdf.

McNaughton, D., Light, J., \& Gulla, S. (2003). Opening up a "whole new world": Employer and coworker perspectives on working with individuals who use augmentative and alternative communication. AAC: Augmentative and Alternative Communication, 19(4), 235-253. Available at: https://doi.org/10.1080/07434610310001595669.

Raišiene, A. G., Rapuano, V., Varkulevičiute, K., \& Stachová, K. (2020). Working from home-who is happy? A survey of Lithuania's employees during the COVID-19 quarantine period. Sustainability (Switzerland), 12(13), 1-21. Available at: https://doi.org/10.3390/su12135332.

Schur, L. A., Ameri, M., \& Kruse, D. (2020). Telework after COVID: A “Silver lining” for workers with disabilities? Journal of Occupational Rehabilitation, 30(4), 52 1-536. Available at: https://doi.org/10.1007/s 10926-020-09936-5.

UKaid. (2020). Impact of COVID-19 on the lives of people with disabilities: Insight and stories from Bangladesh and Kenya. I2i Innovation to Inclusion. Retrieved from: https://www.edf-feph.org/content/uploads/2020/12/i2i-covid19-surveyaccessible.pdf.

UNHCR. (2021). The impact of COVID-19 on daily-wage work and the refugee households that rely on it in the Kurdistan region of Iraq KR-I from: https://reliefweb.int/sites/reliefweb.int/files/resources/IMPACT_UNHCR_Report_Impact\%20of\%20COVID$19 \% 200$ \%20Daily-wage\%20Work_v2.pdf.

United Nations. (2020). Persons with disabilities and coronavirus disease (COVID-19) in Latin America and the Caribbean: Status and guidelines. United Nations, 1-5.

\section{APPENDIX}

\section{Appendix 1: Questionnaire}

Questionnaire for workers who have previously lost one or both arms.

\section{Gender}

1. Male

2. Female

\section{Age bracket}

1. 18-25

2. $26-35$

3. $36-45$

4. 46-55

5. Above 55 years 
3. Level of education
1. Certificate
2. Diploma
3. Bachelors
4. Masters
5. $\mathrm{PhD}$

4. Years spent with the disability
1. $0-5$
2. 6-11
3. $12-17$
4. More than 17

5. Average monthly wages before the pandemic
1. Less than $£ 1000$
2. $£ 1001-£ 2,000$
3. $£ 2001-£ 4,000$
4. Above $£ 4,000$

6. Average monthly wages after the pandemic
1. Less than $£ 1000$
2. $£ 1001-£ 2,000$
3. $2001-£ 4,000$
4. Above $£ 4,000$

7. Were you forced to work from home during the COVID-19 pandemic?
1. Yes, all of the time
2. Yes, some of the time
3. $\mathrm{No}$

8. Did your employer offer any help following new work adjustments during the COVID-19 pandemic?

1. Yes

2. $\mathrm{No}$

9. How has your level of productivity been during the COVID-19 pandemic?

1. More productive

2. About the same

3. Not productive 